\title{
LA ALCUDIA IBÉRICA: UNA NECESARIA REFLEXIÓN ARQUEOLÓGICA
}

\author{
JESÚS MORATALLA JÁVEGA \\ Universidad de Alicante*
}

\begin{abstract}
En el siguiente trabajo se realiza un análisis crítico de la abundante bibliografía que ha generado la excavación de los niveles ibéricos del yacimiento de La Alcudia (Elche. Alicante), acompañado cuando ha sido posible del estudio de determinadas piezas cerámicas que consideramos especialmente adecuadas para trazar una secuencia diacrónica lo más ajustada posible del oppidum ibérico. El objetivo último sería, pues, corroborar o refutar la afirmación según la cual el yacimiento ofrece exactamente la misma estratigrafia en cualquier punto del altozano, hecho que, en nuestra opinión, se compadece mal con los datos publicados a lo largo de décadas.
\end{abstract}

Le travail suivant offre une analyse critique à propos de l'abondante bibliographie publiée sur les fouilles des phases ibériques du site appelé La Alcudia (Elche, Alicante), avec le concours ponctuel de l'étude de quelques tessons céramiques qui peuvent donner une datation très particulière -tous ceux que nous avons pu identifier au musée- pour chaque phase archéologique. II s'agit de corroborer ou réfuter une affirmation traditionelle sur le site: on y trouve la même stratigraphie pour tout le monticule, une hypothèse que nous croyons s'ajuste mal avec la documentation publiée pendant des décennies.

\section{INTRODUCCIÓN}

A lo largo de prácticamente todo el s. XX el yacimiento ilicitano de La Alcudia (Fig. 1) se ha erigido como el referente indiscutible del poblamiento ibérico en tierras alicantinas, o contestanas si se prefiere el topónimo transmitido por las fuentes antiguas, no sólo per se sino también por la trascendencia de su función sobre el territorio circundante: no habia hallazgo ibérico de relieve que en última instancia no buscara en este altozano su razón de ser, hasta el punto que se asumía con naturalidad que aquellos no eran sino un pálido reflejo de lo que se encontraba en La Alcudia, o potencialmente podía hallarse. La bibliografía al respecto es tan abundante que requeriría varias páginas de esta reflexión, de la que eximiremos al lector, sin embargo no nos sustraemos a la tentación de citar al respecto las palabras de E. Llobregat, auténtico padre de la cultura ibérica en estas tierras, para resumir este magnetismo que desprendía el asentamiento: "Posiblemente es ésta la única gran ciudad -si tal puede decirse- de toda la Contestania" (Llobregat Conesa, 1972, 84).

No está en nuestro ánimo efectuar en estas páginas una revolucionaria decons- trucción del yacimiento, pues no suelen ser fructíferos en la explicación científica los movimientos pendulares que van del todo a la nada, además de que sería injusto: ahí seguiría estando la estratigrafía del poblado así como determinados restos arqueológicos sin duda de primera magnitud -pensemos sin más en hallazgos como la escultura de piedra o la vajilla ibérica del Ilamado estilo Elche-Archena, que precisamente recibe parte de su nombre de la ciudad que aloja La Alcudia-. El objeto de este ensayo es otro y pretende sin más actualizar la centenaria información exhumada en el yacimiento a la luz de los avances, tanto metodológicos como epistemológicos, que ha experimentado la ciencia arqueológica en las dos últimas décadas sobre todo. Estos cambios hoy nos permiten precisar con cierta fiabilidad aspectos arqueológicos del máximo interés -procesos estratigráficos, tipos de cultura material, posibilidades interpretativas, etc- que pueden ser trasladados al registro conocido de

\footnotetext{
* Este trabajo ha sido realizado dentro del proyecto de investigación " $\mathrm{De}$ I/ici a Elo. Un proceso de transformación cultural en el sureste de la Península Ibérica" (BHA200202028). Entidad financiadora: Ministerio de Ciencia y Tecnología.
} 


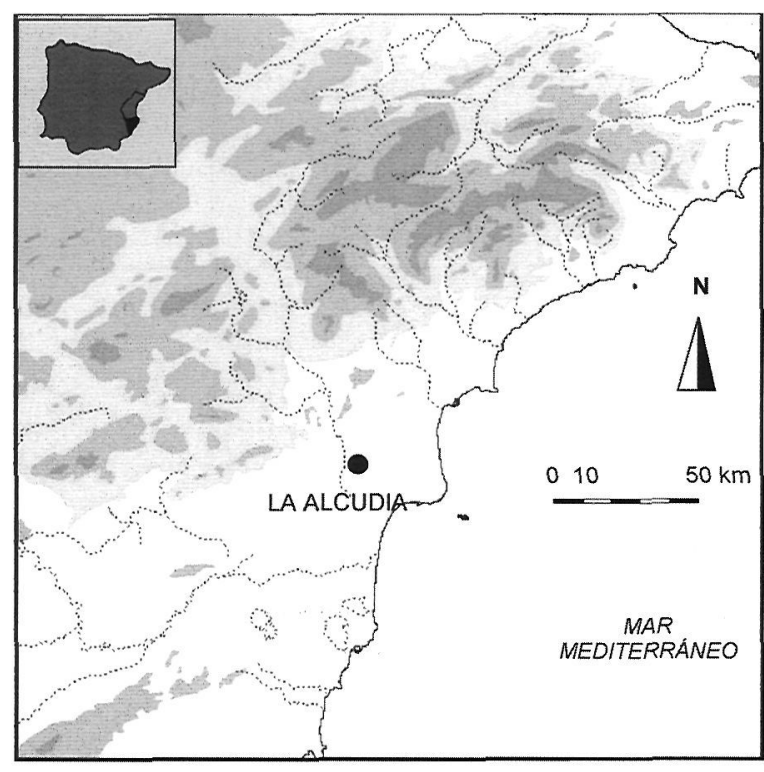

Figura 1: Localización de La Alcudia.

La Alcudia, con el objetivo de reconocer -en el sentido estricto de la palabra- determinados datos que en su día fueron fugazmente comentados y que hoy adquieren un nuevo sentido. Por otro lado, esta disertación pretende igualmente corroborar una circunstancia estratigráfica que reiteradamente ha sido esgrimida en la sucesión de estratos en La Alcudia desde que apareciera publicada la secuencia-tipo del yacimiento (Ramos Folqués, 1966), a saber: la estratigrafía es siempre la misma sea cual sea el sector sondeado. Este dato resulta cuanto menos inusual, pues es sorprendente que un determinado asentamiento mantenga constantemente los mismos límites a lo largo de muchos siglos sea cual sea la categoría de dicho establecimiento; parece razonable preguntarse si, por poner un ejemplo, el asentamiento prehistórico alcanzó las mismas dimensiones que el oppidum ibérico o, mejor, que la colonia romana.

Resulta obvio que la estrategia más apropiada para llevar a cabo este reconocimiento sería un pormenorizado estudio de todas y cada una de las campañas de excavación que han afectado presumiblemente niveles ibéricos, intentando al tiempo una actualizada adscripción tipológica de los materiales encontrados, de manera que en última instancia obtuviéramos un cuadro evolutivo del yacimiento más acorde con las exigencias que hoy en dia plantea la arqueología. La tarea en parte resulta posible, pues se conservan la mayoría de los diarios de excavación así como diferentes conjuntos materiales ordenados en los fondos del Museo
Monográfico de La Alcudia según el año de campaña, pero habrá que reconocer que el volumen de trabajo es sencillamente inabarcable para una persona, al ser susceptibles de estudiar varias decenas de campañas. De manera que la estrategia debe ser otra y se nos ocurre que puede ser ilustrativo analizar "tan sólo" la producción bibliográfica que ha deparado la excavación del yacimiento -que en un $90 \%$ ha salido de manos de la familia Ramos, hasta 1997 propietaria del altozano, siendo por ello prácticamente los únicos investigadores que habian actuado sobre el terreno-, para a partir de ésta y mediante una nueva tafonomía arqueológica -que en su caso puede requerir la observación puntual de distintos restos arqueológicos localizables entre los fondos del museo- alcanzar una visión global de la ciudad, o ciudades, ibérica, siempre parcial en cualquier caso dada la proliferación de sondeos inconexos con que tradicionalmente se ha abordado la excavación en La Alcudia. Es obvio que del grado de coherencia interna que mantenga la estratigrafía tal y como se nos ha presentado, se concluirá una más ajustada valoración de la trascendencia del oppidum ibérico.

Es decir, partimos de un apriorismo no exento de riesgos: la estratigrafía, tal y como reiteradamente se publica, es en esencia correcta, pero contamos con la posibilidad de someter a examen su lógica interna a través de los restos materiales adscritos a tal o cual nivel, que será el objetivo primordial de este trabajo. En realidad, no resulta sencillo otro tipo de aproximación, habida cuenta la ausencia habitual de perfiles o plantas de estrato en las memorias publicadas, de modo que más que optar por una u otra posibilidad, el registro conocido de La Alcudia obliga a una toma de postura casi unidireccional.

A ello dedicaremos por tanto las páginas que siguen, con el ánimo de conseguir responder con el mayor grado de concreción posible a preguntas elementales como el qué, cómo o cuándo en La Alcudia, intentado ubicar en unas coordenadas espacio-temporales más precisas el papel, sin duda preponderante, del yacimiento en su entorno. Para ello traeremos a colación y someteremos a análisis numerosas referencias bibliográficas que ha deparado el asentamiento, recogidas en un primer momento en la tesis doctoral de R. Ramos (Ramos Fernández, 1975) y completadas posteriormente con la memoria de licenciatura de A. Ramos (Ramos Molina, 1997). 

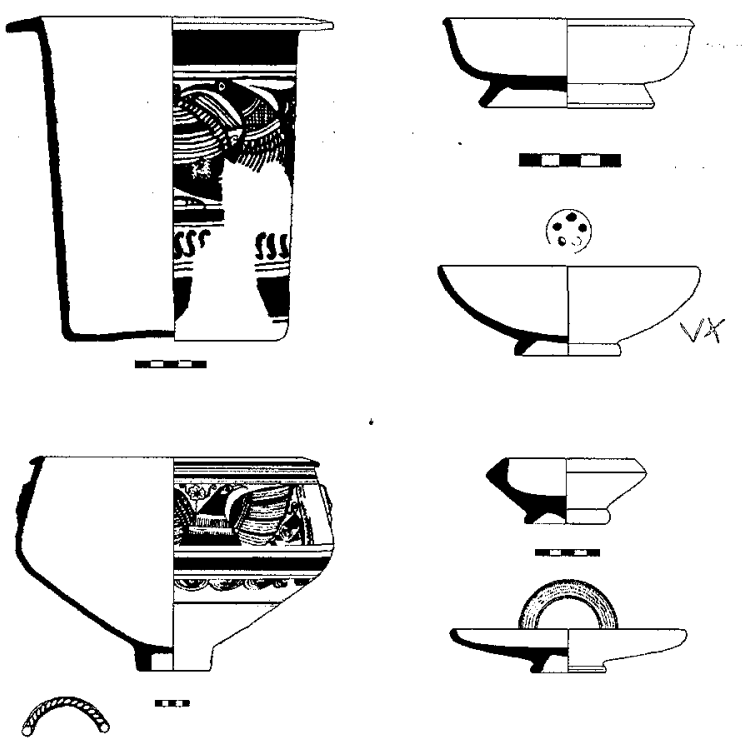

Figura 2: Ajuar cerámico del nivel E (Sala Sellés, 1992).

\section{EL ESTABLECIMIENTO DE UN PUNTO DE PARTIDA}

Un análisis estratigráfico y cronológico como el que pretendemos llevar a cabo resultaría más congruente si fuéramos capaces de establecer una referencia arqueológica grosso modo inamovible que guíe nuestro barrido bibliográfico, un punto de partida que permita centrar y simplificar el problema desde el principio -lo cual nos eximiría de atender los niveles post-ibéricos- y que al mismo tiempo resulte de frecuente aparición y fácil de identificar en el registro arqueológico. Creemos que estas circunstancias convergen en un hito arqueológico indiscutible en este yacimiento: la llamada cerámica Elche-Archena, que ha sido objeto además, a nuestro parecer, del estudio tipológico más riguroso realizado sobre material de época ibérica de La Alcudia (Sala Sellés, 1992). De acuerdo con esta investigación, una parte del ajuar cerámico en uso que ofrece el denominado nivel E -por tanto inmediatamente anterior al nivel $D$ que define tradicionalmente la Colonia Iulia llici Augustase caracteriza, entre otras combinaciones, por la presencia sincrónica de numerosos vasos pintados del denominado estilo Elche-Archena junto a un conjunto de piezas importadas entre las que destacan las cerámicas de barniz negro campanienses A y B (Fig. 2).

Se trata, por lo tanto, de un contexto material relativamente uniforme que convierte a esta cerámica pintada en un verdadero fósildirector para la última fase de ocupación del citado estrato $E$ y que, además, resulta fácilmente identificable en el registro -tanto $E$. Albertini como A. Ramos Folqués en sus primeras intervenciones ya la citan sin ningún género de dudas (Albertini, 1906 y 1907; Ramos Folqués, 1933)-. Ello nos permite, como pretendíamos, simplificar las distintas columnas estratigráficas obtenidas en el yacimiento mediante el establecimiento de un horizonte ante quem que, de acuerdo con el estudio de F. Sala, debe situarse a principios del s. I aC como datación final para el citado nivel. Cabe la posibilidad que dicha cronología pueda retrasarse un tanto, haciéndola coincidir con el establecimiento de la colonia romana ${ }^{1}$, no obstante consideramos que, para el tema que nos ocupa, este hecho no afecta excesivamente a nuestros objetivos que, recordemos, se centran en determinar las distintas fases ibéricas, siendo este nivel E el último que como tal puede considerarse. Por otro lado, es una cuestión documental que a día de hoy todavia se encuentra abierta y que requeriría de nuevas intervenciones arqueológicas. Hay que recordar que son muy escasos y antiguos los indicios materiales que permiten retrasar la fecha final de este estrato hasta la segunda mitad del s. I $\mathrm{aC}$-apenas un par de citas refieren el hallazgo de fragmentos de cerámicas sigillatae en los niveles correspondientes a este estrato $E$ (Ramos Folqués, 1941 y 1943), además del pequeño lote del mismo material hallado en el estrato superior del denominado "templo ibérico" (Ramos Fernández, 1995)-, por lo que conviene apelar a la prudencia en este caso y esperar, insistimos, nuevas investigaciones que aquilaten desde la arqueología los datos que proporcionan las evidencias epigráficas.

La conclusión sería, por lo tanto, que el nivel que proporciona la cerámica ElcheArchena, que aparece por doquier en el yacimiento, alcanzaría hasta un momento indeterminado del s. I aC, luego esta referencia nos permite fijar un horizonte cronológico, y espacial en el propio yacimiento, a partir del cual desandar la estratigrafía para reconstruir las fases anteriores. Se puede argüir, con cierta razón, que puede resultar arriesgado fijar nuestra premisa de partida a partir de un elemento arqueológico que puede evolucionar y mostrar diferentes estadios formales, pero no

\footnotetext{
1 Véase al respecto la reciente reflexión de G. Alföldy sobre la fecha de establecimiento de la colonia ilicitana, una auténtica joya bibliográfica a propósito del análisis de las fuentes escritas y, sobre todo, epigráficas (Alföldy, 2003).
} 


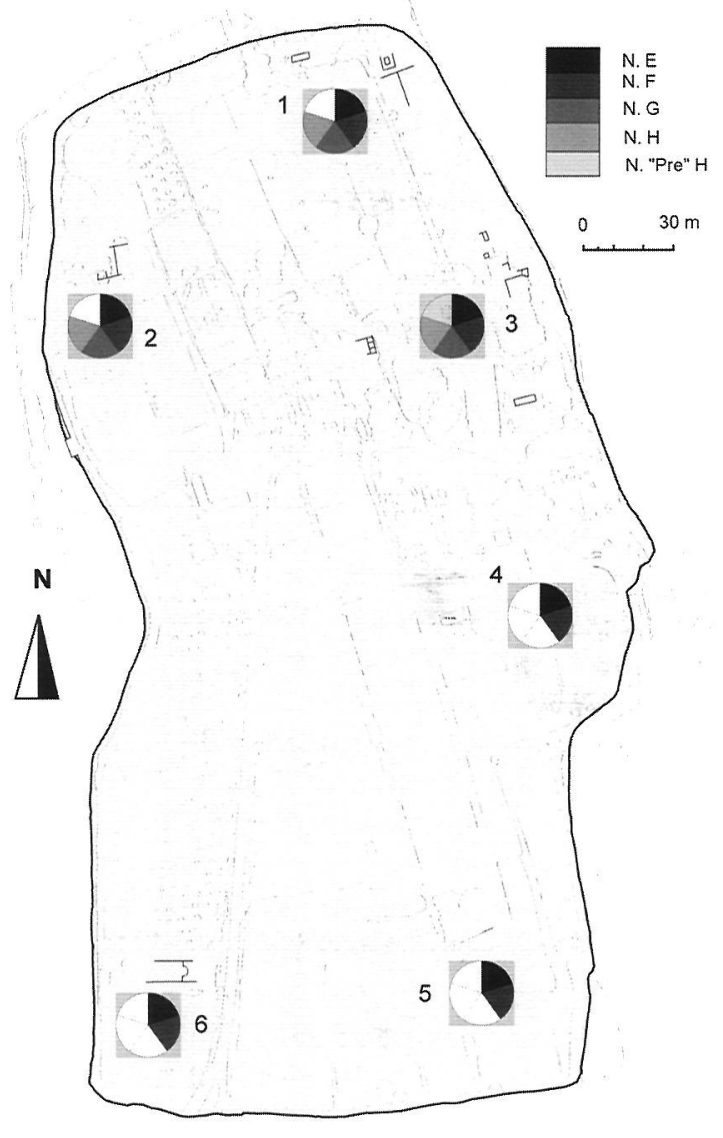

Figura 3: Planta de La Alcudia con indicación de los sectores excavados (elaborado a partir de Ramos Molina, 1997).

es menos cierto que el estilo mal llamado de Elche-Archena ${ }^{2}$ ofrece suficientes rasgos compositivos como para identificarlo con bastante certidumbre, como el propio A. Ramos Folqués demostró en su última obra (Ramos Folqués, 1990). Estamos convencidos de la utilidad del método empleado habida cuenta, insistimos, que nos encontramos ante series estratigráficas teóricamente individualizadas a partir del hallazgo de pavimentos pero que no vienen acompañadas de las necesarias plantas, secciones o perfiles, luego no son muchas las opciones de que disponemos.

Una vez aceptado este principio, el paso siguiente iría dirigido a cartografiar en la planta de La Alcudia los distintos sectores donde se localiza dicho material de acuerdo con las memorias y noticias publicadas, para a partir de aquí continuar las series estratigráficas en profundidad y proceder a un ejercicio comparativo de todas ellas de las que obtener las conclusiones finales. La planta del poblado elegida para esta fase del estudio será sin duda la publicada por A. Ramos Molina en 1997 (Fig.
3), levantada por un equipo de topógrafos y bastante más precisa que otras planimetrías publicadas con anterioridad. Esta circunstancia provoca no obstante una cierta discordancia respecto a las memorias publicadas hasta esa fecha, que utilizan casi siempre un sistema de cuadrícula con abscisas y ordenadas para identificar la zona intervenida; procuraremos obviar este problema distinguiendo con claridad en la planta utilizada la zona a la que se refiere la cita relatada.

\section{ARQUEOLOGÍA BIBLIOGRÁFICA}

\section{1. La "ciudad" del estrato E}

La cerámica Elche-Archena aparece y se identifica con claridad en cualquiera de los sondeos abiertos en la loma, hallazgo que además viene acompañado del correspondiente pavimento -generalmente un piso de arcillaque otorga carta de naturaleza a un determinado nivel constructivo, en este caso y como hemos señalado, el estrato E. Concretando un poco, este tipo cerámico -muy abundante por otro lado $^{3}$ - aparece en sondeos localizados en las cuadrículas $3 F$ (Fig. 3, 1), 4C (Fig. 3, 2), 5F (Fig. 3, 3), 6F y 7F (Fig. 3, 4), $10 \mathrm{D}$ (Fig. 3,5 ) y $10 \mathrm{~A}$ (Fig. 3,6 ) y está con frecuencia asociado, además de a la cerámica de barniz negro campaniense, con ases romanos del tipo Jano y proa y otros con leyendas ibéricas, cerámica de paredes finas o megárica de relieves y ánforas de la serie Dressel 1, además de la constatación del reempleo de fragmentos escultóricos como mampuestos de algunas casas. Sin duda puede defenderse que el ítem se documenta por todo el altozano, de norte a sur y de este a oeste, lo que permitiría postular a la vez que la ciudad productora de estos recipientes y último establecimiento ibero estrictamente hablando -de la que se conoce además la planta

\footnotetext{
2 Suscribimos la hipótesis de T. Tortosa a propósito de la necesidad de diferenciar las producciones ilicitanas de las procedentes del área murciana, pues proceden claramente de al menos dos talleres, uno de los cuales sin duda radicó en La Alcudia. Consúltese igualmente la citada obra, $u$ otras de la misma autora, para un mejor conocimiento de las características de dicho estilo pictórico (Tortosa Rocamora, 1998).

${ }^{3}$ En el citado trabajo de T. Tortosa se estudian nada menos que 170 piezas de este estilo procedentes de La Alcudia (Tortosa Rocamora, 1998, 208).
} 


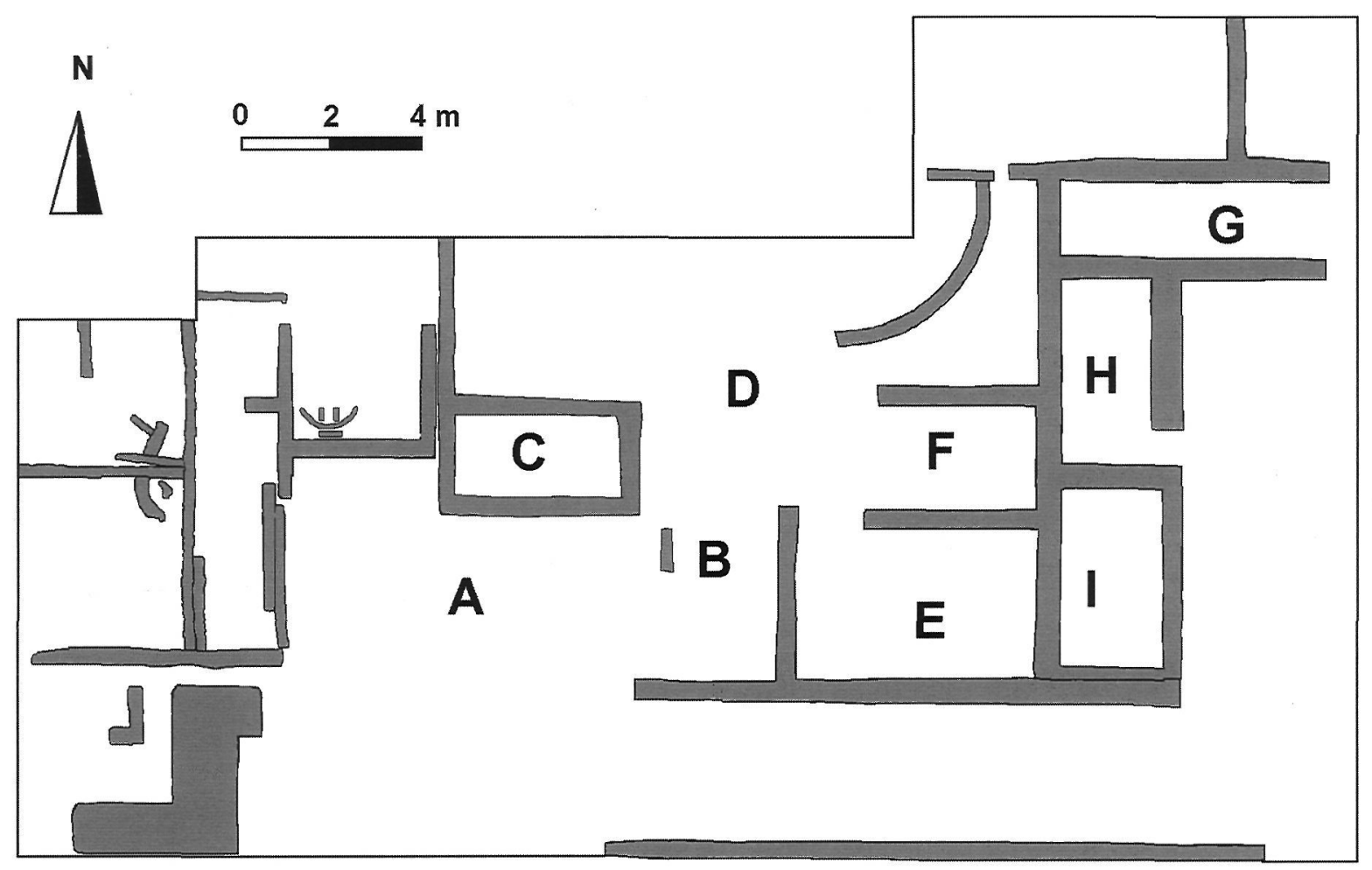

Figura 4: Planta del sector 4C; nivel E (elaborado a partir de Ramos y Ramos, 1976).

arquitectónica de mayores dimensiones excavada de esta ciudad, situada en el sector 4C (Fig. 4)-, se extendería por todo el altozano. Aquí se produce un primer elemento de discusión y es el referente a la extensión de dicha ciudad.

Desde las primeras publicaciones se ha afirmado que las dimensiones del altozano, y por tanto del yacimiento encerrado en el mismo, rondarían las $10 \mathrm{Ha}$ (Ramos Folqués, 1944). Desconocemos los cálculos o datos manejados para llegar a tal conclusión, lo que sí estamos en condiciones de asegurar es que la planta publicada en 1997 presenta para el altozano unas dimensiones en torno a las $6 \mathrm{Ha}$. Ello se obtiene aplicando una sencilla cuadrícula transparente sobre el plano prácticamente horizontal del asentamiento y contabilizando los cuadros integrados en la loma que, a su vez, son de un determinado tamaño de acuerdo con la escala de la planta. La diferencia es por tanto notoria, no obstante lo cual conviene recordar que aun con estas cifras, La Alcudia sigue siendo de lejos -dobla como mínimo el siguiente asentamiento en tamaño (Abad et alii, 2001; Moratalla Jávega, 2003 y e.p.)- el mayor núcleo habitado del poblamiento ibérico alicantino, lo que obviamente relativiza un tanto la importancia del dato que ahora analizamos. En cualquier caso mantendremos la cifra propuesta por nosotros que, a su vez, servirá de referencia para otros cálculos ulteriores.

A partir de estos datos comienza la auténtica "arqueología bibliográfica" a la que se refiere el título de este epígrafe.

\section{2. La "ciudad" del estrato F}

Comenzando por el sector 3F (Fig. 3, 1), donde hoy se exhibe una de las principales domus romanas descubiertas en La Alcudia, se describe la presencia inmediata por debajo del nivel $E$ de un estrato que contenía cerámicas ibéricas comunes (en adelante $\mathrm{CM}$ ), de cocina (CC) y fragmentos pintados (PT), uno de ellos imitando una forma griega como es el kylix y otro decorado con hojas (Ramos Folqués, 1966, lám. III, foto 4; Ramos Fernández, 1975). Se trata del tradicional nivel $F$ identificado en el yacimiento, el cual contiene como se puede comprobar materiales arqueológicos excesivamente comunes tanto para intentar datar el inicio del estrato E como para concretar la

\footnotetext{
4 Obviamente pensamos en proyectos urbanos diligentemente llevados a cabo, sin considerar la posibilidad de que existan refacciones, ampliaciones, alteraciones, etc., de esa planimetría. Esta información no puede aprehenderse hoy por hoy en el yacimiento, dada la frecuente desconexión física de los cortes abiertos.
} 
cronología del propio estrato $\mathrm{F}$ más allá de una atribución genérica a época ibérica plena. Además, dicho sondeo muestra un tipo de información que será una constante a lo largo de casi todos los cortes abiertos, esto es, sólo se encuentran unidades sedimentológicas, sin que existan apenas menciones relativas al hallazgo de estructuras relacionadas con aquéllas más allá de la consabida cita del hallazgo de un pavimento de arcilla o tierra apisonada, que es el horizonte que va marcando el tránsito de niveles.

Siguiendo con el cuadro 4C (Fig. 3, 2), un área abierta excavada con bastante amplitud donde hoy se exhiben las llamadas "casitas ibéricas" (Fig. 4), son varios los sondeos realizados y por tanto más rica la información de la que disponemos.

En las primeras actuaciones en profundidad (Ramos Folqués, 1962a; Ramos y Ramos, 1966), por debajo del nivel E, que deparó entre otros el conjunto estudiado por F. Sala (Sala Sellés, 1992) además de cerámica campaniense A, de Gnathia, gris ampuritana ${ }^{5}$ y algún as romano del tipo Jano bifronte, se localiza una nueva fase con fragmentos de ánforas (ANF), CM, PT -alguna pieza decorada con motivos fitomorfos e incluso un fragmento con cuadrúpedos- asi como nuevamente la GR ampuritana y la Camp. A, en concreto se identifica de este último tipo la forma 27 de Lamboglia ${ }^{6}$. Huelga comentar que de comprobarse efectivamente la existencia de esta última producción estariamos situando los inicios del nivel $E$ en pleno $s$. II aC o incluso en el tránsito de esta centuria con el III aC (Olcina y Sala, 2000), que es por otro lado la datación tradicional otorgada al citado estrato.

Las campañas realizadas entre 1968 y 1973 en este mismo sector son recogidas en una de las publicaciones más completas sobre el yacimiento, al menos en cuanto a la descripción de materiales, lo que permite a priori precisar bastante las horquillas cronológicas (Ramos y Ramos, 1976). En la primera de ellas se alcanza, bajo el estrato $E$ insistimos, un nivel $\mathrm{F}$ con cerámicas PT y CC y además se citan (Fig. 5, 3-4) sendos bordes de Camp. A de las formas Lamb. 22 y 28 (Ramos y Ramos, op. cit., fig. 13, c y d) ${ }^{8}$. En 1969 sólo se destaca la presencia de cerámica $\mathrm{PT}$. Al año siguiente aparecerá un repertorio más rico en el que, además de la PT y las ANF, se documenta la presencia de cerámica GR y la base de una crátera ática de barniz negro (BN). En 1971 se vuelve a repetir la presencia de cerámica $\mathrm{CM}, \mathrm{CC}$,
PT -algún fragmento con decoración fitomorfay ánforas ibéricas con marcas de escobillado en sus hombros, que últimamente vienen recibiendo, creemos que con razón, el apelativo de "contestanas" (Álvarez García, 1997). De corroborarse los datos relatados, volveríamos a una horquilla cronológica de principios del s. $\mathrm{II}$, tal vez incluso antes, para el final del estrato $\mathrm{F}$ que, sin solución de continuidad, proseguiría con la ciudad tardo-ibérica.

La campaña de 1973 en este mismo sector resulta de gran interés, pues demuestra a nuestro juicio la existencia de fases constructivas intermedias dentro de la estratigrafía tradicional de La Alcudia, datos que tal vez haya que interpretar como refacciones de limitada amplitud en determinados sectores del yacimiento. Así, por debajo del Nivel E se cita el hallazgo de un estrato con cerámicas PT -alguno con decoración fitomorfa-, ANF contestana, ANF grecoitálica ${ }^{9}$ (Ramos y Ramos, 1976, lám. LXXIX, 1) y un posible guttus agallonado de BN (Ramos y Ramos, op. cit, lám. LXXXI, 1). En principio, la sucesión estratigráfica no se saldría de los parámetros establecidos hasta ahora si no fuera porque por debajo de este estrato aparece otra fase -denominada Nivel G.u, siguiendo los criterios ha-

\footnotetext{
${ }_{5}^{5}$ Mantenemos la identificación propuesta por estos autores aunque somos conscientes de la necesidad de un reestudio detallado de estos tipos cerámicos, especialmente adecuados para ofrecer cronologias más concretas.

${ }^{6}$ La pieza no ha podido ser identificada entre los fondos del Museo de La Alcudia. Aprovechamos la ocasión para agradecer a Mercedes Tendero, arqueóloga de la Fundación Universitaria de Investigación Arqueológica "La Alcudia", los desvelos y facilidades ofrecidas para la localización de las piezas demandadas por quien esto suscribe, sin duda una ardua tarea.
}

${ }^{7}$ Representamos las piezas tal y como fueron publicadas, esto es, sin escala gráfica. Cabe la posibilidad en el caso de las ánforas que la línea rematada en ángulo recto sobre la que se apoyan los bordes indique el diámetro de las mismas, no obstante y comprobando el original, esta medida oscilaría respectivamente entre 7 y $8 \mathrm{~cm}$, lo que obviamente se nos antoja un diámetro excesivamente pequeño.

${ }^{8}$ Al igual que la anterior, no hemos podido localizar dichas piezas, si bien la primera -por su forma 22- debe ser una producción ática. Agradecemos a la Dra. Sala Sellés sus observaciones sobre ésta y otras cuestiones del material importado de La Alcudia.

- Al parecer seria de la variante clásica, aunque la antigua está también atestiguada en La Alcudia en el estudio que J. Molina realiza sobre las ánforas importadas del yacimiento (Molina Vidal, 1997, lám. 12, LA-276). Agradecemos al Dr. Molina la posibilidad de consultar material inédito de su tesis asi como las observaciones realizadas al respecto. 

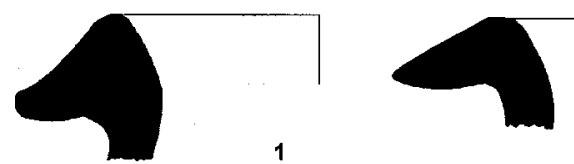

1 2

3

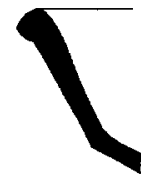

Figura 5: Ánforas y cerámicas de barniz negro importadas (Ramos y Ramos, 1976).

bituales, horizonte ibérico antiguo- en la que se documenta la presencia de ánforas magno greco-siciliotas (ibid., fig. 47, a y b), dos bases identificadas como Camp. A antigua (ibid., fig. 51 , e y g), un ánfora de posible origen griego (ibid., fig. $48, \mathrm{c}$ ) y también un mortero ebusitano (ibid., lám. LXXXIX, 3) de los que J. Ramón identifica como del taller AE-20 (Ramón, 199091).

En lo referente a las ánforas de la Magna Grecia, la primera (Fig. 5, 1) podría entrar en las variante MGS VI de Vandermersch, datable hacia el último tercio del $\mathrm{s}$. III aC (Vandermesch, 1994, 83), mientras la segunda se acerca más a la variante MGS IV (Fig. 5, 2), cuya cronología abarcaría todo el s. IV y principios del III aC (Vandermesch, op. cit., 74); un segundo borde de esta última variante se ha identificado en las vitrinas del Museo de La Alcudia (Fig. 6, 1) ${ }^{10}$. En cuanto a la cerámica "campaniense", afortunadamente hemos podido identificar las bases en el museo, presentando las siguientes características de producción: pasta anaranjada de textura dura y homogénea, con frecuentes vacuolas, desgrasante apreciable (trazas negras, blancas y micáceas) y barniz algo diluido de tono castaño, con manchas y poco brillante (Fig. 6, 2), y pasta anaranjada-castaña de textura muy dura y homogénea con alguna vacuola, desgrasante inapreciable (con las mismas trazas citadas) y barniz negro homogéneo con iridiscencias metálicas (Fig. 6, 4). La falta del borde nos impide precisar la forma pero parece indudable que nos encontramos ante dos tipos de producciones, la primera entraría de lleno en la serie de la campaniense A antigua, y posiblemente sea una típica forma 27 de finales del III-principios del $\mathrm{s}$. II aC, mientras la segunda ofrece una mayor calidad que le acerca más a las producciones del s. III aC de los "Talleres de Rosas",
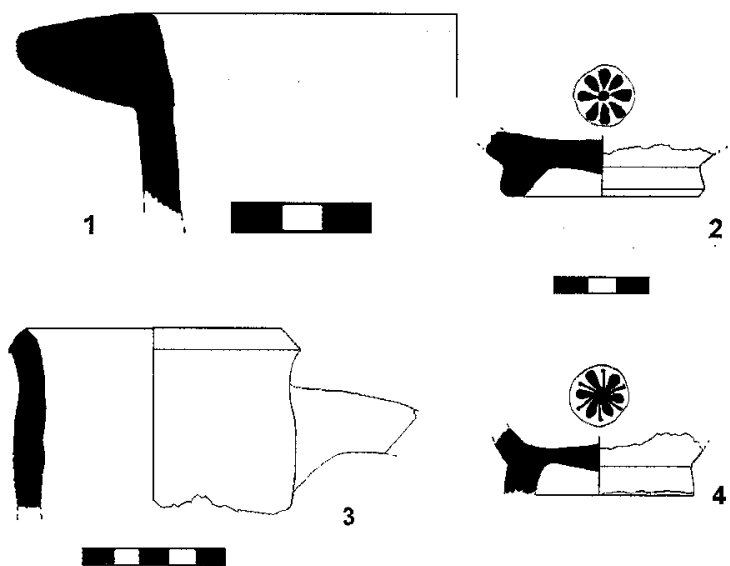

Figura 6: Ánforas y cerámicas de barniz negro importadas.

donde encontramos paralelos idénticos para la roseta con estambres que adorna su fondo interno (Sanmartí-Grego, 1978, fig. 7, 30-31; Principal-Ponce, 1998, lám. 9, 6).

Por lo que respecta al ánfora no identificada (Fig. 6, 3), la pasta castaña con numerosas trazas blancas, su borde poco destacado y triangular, el cuello cilíndrico y la existencia de un manchón de pintura roja por encima del arranque del asa plantea como posibilidad, sin más, un origen quiota (Arribas et alii, 1987, 471).

Todas estas piezas referidas apuntan hacia un contexto de finales del s. III o principios del II aC, cuando teóricamente -de acuerdo con la secuencia-tipo- deberíamos encontrarnos en uno del $\mathrm{V}$ aC. Ello significaría, a su vez, que el nivel $F$ identificado en esta campaña de 1973 sería muy probablemente del s. II $\mathrm{aC}$, informando sobre una posible refacción arquitectónica que habría tenido lugar en una fecha indeterminada de dicha centuria. Sería así un estrato intermedio que pone de manifiesto posiblemente la existencia de remodelaciones parciales en el urbanismo de la ciudad, que deberían resultar poco sorprendentes habida cuenta la larga perduración del asentamiento, superando así el encorsetamiento al que obliga una secuencia-tipo llevada hasta sus últimas consecuencias de una manera un tanto imprudente, además de innecesaria. Es probablemente el mejor ejemplo al respecto que encontramos en las estratigrafías publicadas y ello tiene que ver sin duda con la mejora en la presentación de los datos, sobre todo en la parte

10 Pasta dura y compacta, de tacto rugoso y coloración castaño-granate, con engobe interno y externo ocre; desgrasante de pequeño tamaño pero abundante: trazas negras, granates y micáceas. NInv.: LA-796. 
gráfica, que presenta esta interesante memoria.

Por debajo de este "estrato G" se menciona uno más que incluiría tan sólo materiales cerámicos $\mathrm{CM}, \mathrm{CC}, \mathrm{PT}$, ANF y urna de orejetas, que tal vez podría corresponder propiamente al horizonte de la fase ibérica plena.

Las excavaciones en el sector 5F (Fig. $3,3)$, por debajo de una nueva domus romana situada inmediatamente a levante del actual museo, cuentan por otro lado con una interesante secuencia estratigráfica en lo que se refiere a restos constructivos, bien presentada en dos artículos sucesivos de R. Ramos (Ramos Fernández, 1982 y 1983a). Ya con anterioridad (Ramos Folqués, 1966) se había constatado un estrato infrapuesto al tradicional $E$ que contenía, entre otros, fragmentos de cerámicas áticas de BN y de figuras rojas (FR); el lote es aumentado por $\mathrm{R}$ Ramos citando la aparición de fragmentos PT -alguno decorado con pecesy $\mathrm{CM}$, así como la posible existencia de un pavimento de adobes de una estancia limitada por su zona este "por un gran muro, posible defensa exterior de la ciudad" (Ramos Fernández, 1983a, 167-171, fig. 4). No ofrece por otro lado este nivel una mayor concreción cronológica, si acaso parece que la decoración zoomorfa tiende más a un contexto del III que del s. IV $\mathrm{aC}$, por lo que grosso modo se mantendría en la horquilla propuesta más arriba.

El estudio de los sectores 6F y $7 \mathrm{~F}$ (Fig. $3,4)$, puede ser abordado de forma conjunta dado que son por completo adyacentes, situándose en la vertiente oriental del altozano si bien su huella hoy no es visible, presumiblemente porque fueron tapados una vez excavados. Los primeros sondeos (Ramos Folqués, 1966) manifestaron por debajo del nivel E la presencia de cerámica PT -con fragmentos fitomorfos y también alguno bícromo- junto a fragmentos áticos de BN (Ramos Folqués, op. cit., lám. VIII, 1). Es de reseñar que en publicaciones anteriores describe la existencia de un lienzo de muralla de 1'5 m de grosor cubierto por el estrato $E$ (¿sería la misma posible fortificación citada en el anterior párrafo?), donde se hallaron, muy posiblemente reutilizados, fragmentos escultóricos del cuerpo de una leona, una probable cabeza de sirena o koré y elementos arquitectónicos (Ramos Folqués, 1956); en cualquier caso, la conexión estratigráfica entre construcciones y materiales no queda del todo clara. Tampoco es un sector del que se puedan derivar conclusiones sólidas respecto a la cronología.
Por lo que se refiere al sector 10D (Fig. $3,5)$, el más cercano al lugar donde se descubrió la Dama, las excavaciones ya cuentan con un antiguo precedente como fue la actuación de E. Albertini (Albertini, 1906 y 1907), cuya figura es preciso reivindicar pues no en vano publicó detalladamente todo aquello que encontró, al menos en el apartado cerámico, lo que le otorga un mérito indudable; cuestión aparte es el rigor metodológico empleado en sus trincheras y ciertamente parece que contaba con algunas carencias en su formación, por otro lado habituales entre los investigadores de principios del s. XX, pero de sus escritos es posible inferir algunas cuestiones interesantes. Efectivamente afirma que todos los estratos estaban mezclados y que no es posible establecer una secuencia pero, al mismo tiempo, también declara que en las trincheras I -aproximadamente hacia el cuadro $7 \mathrm{C}$ - y II -en este sector 10D- encuentra en los últimos $30 \mathrm{~cm}$ sólo cerámica $\mathrm{PT}$ geométrica, sin rastro de la figurada, por lo que bien pudiera interpretarse como el tradicional nivel F. Además, es el único investigador que identifica con precisión el nivel de base pues lo define como un estrato de arenas y arcilla estéril ${ }^{11}$, obviamente más preciso que la frecuente alusión a "tierra virgen" con que se denomina en el resto de publicaciones.

Después, las excavaciones de A. Ramos Folqués vuelven a documentar bajo el nivel de la cerámica figurada ollas de CC (Ramos Folqués, 1962b, 92), ANF contestanas, PT -un fragmento con decoración zoomorfa- y BN ático (Ramos Folqués, 1966, lám. XVI), todo ello, según el texto, encima de la tierra virgen del terreno (Ramos Folqués, 1966, 74), lo que, como es de esperar, resulta de gran trascendencia para la secuencia estratigráfica del yacimiento.

Para finalizar, el último sector que debe ser traído a colación es el situado en la cuadrícula 10A (Fig. 3, 6), más conocido por servir de asiento a la basílica paleocristiana que, a su vez, se levanta según parece sobre los restos de lo que podría ser un recinto de carácter sacro de época ibérica. Antes de entrar a examinar la documentación alcanzada en este edificio, merece la pena recordar las intervenciones arqueológicas llevadas a cabo inmediatamente al sur de este espacio, pues en este pun-

\footnotetext{
11 Este mismo estrato de base ha sido documentado en los sondeos geológicos realizados en 2003 en la parte occidental del altozano, donde se levantará el futuro Museo de La Alcudia.
} 

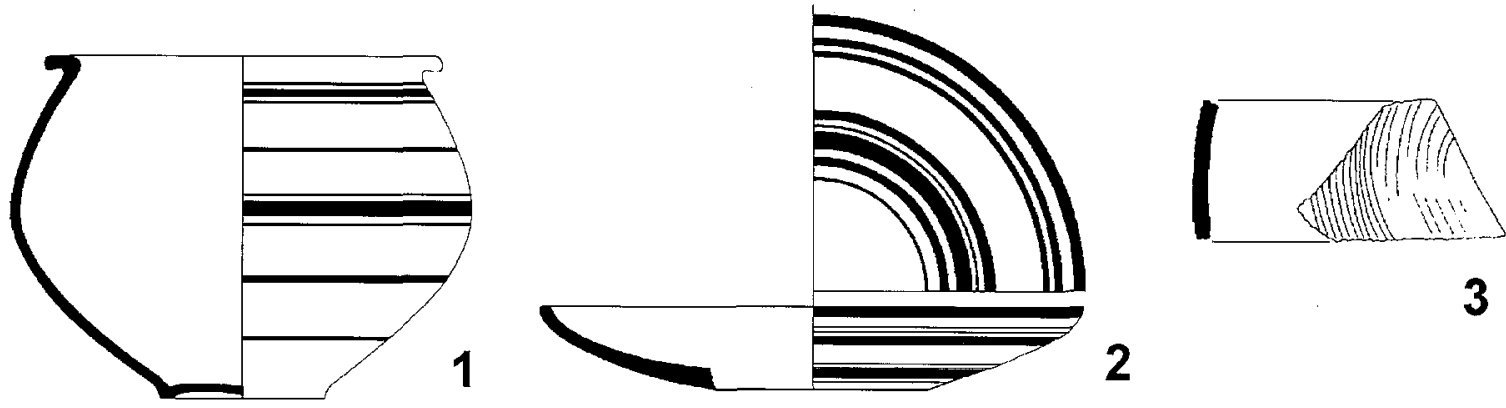

2
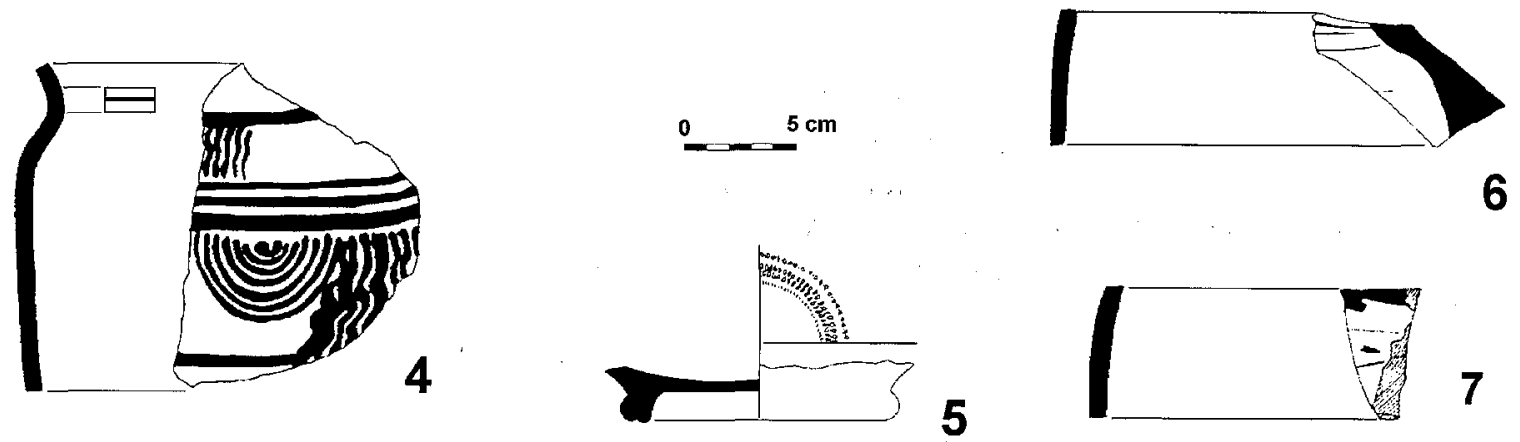

5

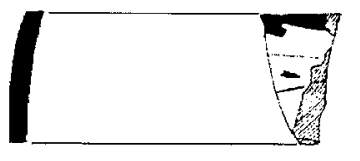

7

Figura 7: Ajuar cerámico de la primera fase del "templo" ibérico; nivel F (Ramos Fernández, 1995).

to se identificó una posible calle en cuyo empedrado se han reutilizado innumerables fragmentos escultóricos de época ibérica (Ramos Folqués, 1950). Este elemento del entramado urbano tiene al parecer en época romana su fase más reciente de construcción -pertenece por tanto al nivel D-, siendo de destacar que todavía a finales del s. I aC los fragmentos de esculturas ibéricas sirven como base del pavimento de estas calles. Este vial se levantaría sobre otro de similar anchura relacionado con la cerámica de tipo Elche-Archena y que, de nuevo, presenta trozos escultóricos sirviendo como firme. Por debajo de esta última calle $A$. Ramos Folqués encuentra fragmentos de ANF contestana, PT -alguno con decoración vegetal y uno con la figura de un cérvido-, CC, un thymiaterium del tipo de cabeza femenina, fragmentos de cerámica ática de $\mathrm{BN}$ y, en palabras del autor, "un plato campaniense con círculos blanquecinos en la base", descripción ésta que nos resulta insuficiente para poder precisar el tipo al que se refiere, de lo contrario es posible que la pieza resultara un buen indicador cronológico.

Como queda dicho, más amplia es la información con que contamos en lo referente a los templos ibéricos, pues la publicación de los mismos (Ramos Fernández, 1995) ofrece una pormenorizada descripción del registro cerámico hallado, incluyendo sus dibujos. Dejando de lado la fase más moderna del edificio adscrita al nivel E, hemos aprovechado la ocasión para realizar un somero cálculo estadístico de los tipos cerámicos encontrados en el nivel fundacional, esto es el $F$, teniendo en cuenta sólo los fragmentos que presentaban borde ${ }^{12}$.

De esta manera se puede comprobar que el tipo más representado es la cerámica PT y, dentro de ésta, los platos, que con un $45^{\prime} 5 \%$ suponen casi la mitad del total de piezas halladas (Fig. 7, 1). Por detrás se encuentran las tinajas o pithoi PT con un porcentaje del $23 \%$. Quiere ello decir que casi tres cuartas partes del total de piezas halladas en el estrato más antiguo del templo corresponden a elementos de vajilla doméstica y grandes contenedores. El resto de formas se reparten entre los kalathoi PT y piezas únicas de cerámica PT bícroma, CC o ANF contestana, todos los cuales suman alrededor del $12 \%$ del total (Fig. 7, 3-4). Por lo que se refiere a la cerámica importada (Fig. 7 , 5-7), se contabilizan dos fragmentos de BN ático y tres de FR $-11 \%$ del total-, amén de dos fragmentos de escultura -sendos brazos- y una moldura arquitectónica con decoración vegetal, que representan sin lugar a dudas los ejemplos de este material mejor contextualizados de todo el yacimiento.

12 Obviamente partimos de la base de que el texto publicado recoge absolutamente todo el material cerámico encontrado. 
El registro permite proponer con argumentos arqueológicos la fase de ocupación que representa el nivel F. En este sentido nos enfrentamos ante las diferencias surgidas entre los propios excavadores sobre la cronología de los templos. La primera noticia relativa a los mismos (Ramos y Llobregat, 1995) concluye proponiendo una ocupación de los ss. III-I aC para la fase reciente mientras la original no se concreta. Años después R. Ramos sitúa la cronología inicial del edificio hacia finales del s. VI aC (Ramos Fernández, 1995), aduciendo como principal y único argumento la existencia de un capitel protoeólico reutilizado en un paramento de la basílica paleocristiana que presumiblemente pertenecería a la entrada del edificio ibérico, elemento para el que encuentra paralelos en contextos del s. $\mathrm{VI}$ aC en el Mediterráneo oriental. No obstante creemos, como el mismo E. Llobregat propuso ya en su día (Llobregat Conesa, 1994, 174), que la fase original del edificio no superaría, como muy antiguo, el último tercio del s. $\mathrm{V}$ aC, siendo posible que alcanzara hasta el III aC en este primer horizonte de ocupación. Esta hipótesis se fundamenta en que el registro arqueológico encontrado es homogéneo, compacto, muy propio de un determinado momento histórico y no de otro y en este caso no encontramos ningún elemento material que permita adelantar la construcción hasta el s. VI aC. La cerámica PT y sus altos porcentajes, el carácter residual de la decoración bícroma, los fragmentos áticos importados, la notable ausencia de la cerámica GR, todo ello conduce a una horquilla como la propuesta, descartando por lo tanto la existencia de una fase antigua en este edificio.

Concluyendo con este nivel, puede postularse pues la hipótesis sobre la existencia de un estrato inferior al nivel $E$ que aparecería prácticamente por todo el altozano, luego no parece que el asentamiento de época tardía supere en tamaño al de la fase plena, que rondaría por tanto las $6 \mathrm{Ha}$ propuestas, siendo así, como se ha señalado, el mayor oppidum ibérico de tierras alicantinas. Es de anotar por otro lado la casi absoluta falta de restos constructivos de este horizonte pues éstos se reducirían a la planta inicial del posible templo y los restos de la ladera oriental, tal vez una batería de habitaciones adosadas a una fortificación. La imagen por tanto de su diseño urbano se nos escapa por completo y no habría que descartar ninguna posibilidad sobre su plasmación física, en concreto nos planteamos si el edificio de culto señalado se integraría en dicha malla o si por el contrario aparecería desplazado y perfectamente individualizado del paisaje urbano.

En lo referente a la sucesión cronológica de ambos horizontes, en primer lugar es preciso reseñar que nunca se cita un estrato estéril que separe los niveles $E$ y $F$, luego hemos de suponer que no transcurrió apenas tiempo entre el fin de uno y el comienzo del otro; su sucesión habría sido inmediata y mecánica. No es fácil fijar la datación de esta transición; hemos visto que entre los materiales del nivel $F$ se citan con relativa frecuencia las cerámicas PT decoradas con motivos vegetales e incluso zoomorfos -de una temática y estilo claramente diferente a la cerámica Elche-Archena- y también piezas de barniz negro identificadas como campanienses $A y$, tal vez, de los talleres de Rosas, además de algunas ánforas importadas bien fechadas como la serie magnogrecosiciliota o la grecoitálica. Son elementos materiales que, de confirmarse su origen, postularían un final para este estrato $\mathrm{F}$ a caballo de los ss. III y II aC, luego en este sentido la cronología tradicional sería efectivamente correcta. Por otro lado, se constata igualmente la ruptura de la serie estratigráfica tradicional en algunos puntos, especialmente en el sector $4 \mathrm{C}$, lo que resulta bastante más razonable que suponer que una gran ciudad, como debió ser La Alcudia ibérica, no modificó en absoluto su fisonomía durante décadas.

\section{3. La "ciudad" del estrato G}

Si hasta ahora la estratigrafía de La Alcudia ha mostrado una secuencia a grandes rasgos similar y extendida prácticamente por toda la loma, a partir del horizonte F la sucesión en profundidad de los niveles ofrece lecturas diversas, desde la aparición de estratos estériles hasta el desarrollo de secuencias más largas, pasando por zonas en las que no resulta prudente manifestarse al respecto dado que, al parecer, los sondeos no alcanzaron toda la profundidad posible. La evaluación del nivel $\mathrm{G}$ lleva implícita por otro lado la consideración sobre la fase ibérica antigua de La Alcudia, para la que contamos con claros indicios tanto cerámicos como constructivos, algunos de los cuales (Fig. 8) ya han sido presentados de manera sistemática (Tendero Porras, e. p.).

Siguiendo el mismo orden establecido en el epígrafe anterior y comenzando por el sector $3 F$, por debajo del estrato $F$ se localizan tan sólo fragmentos de cerámica ibérica PT (Ra- 

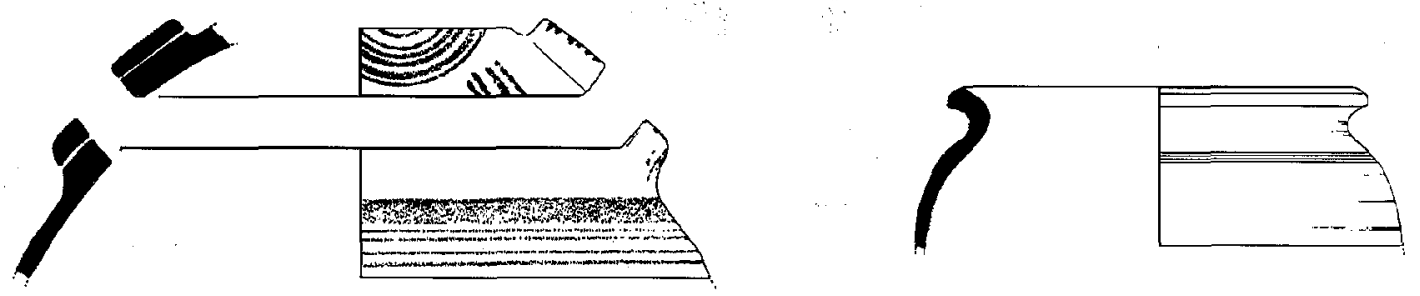

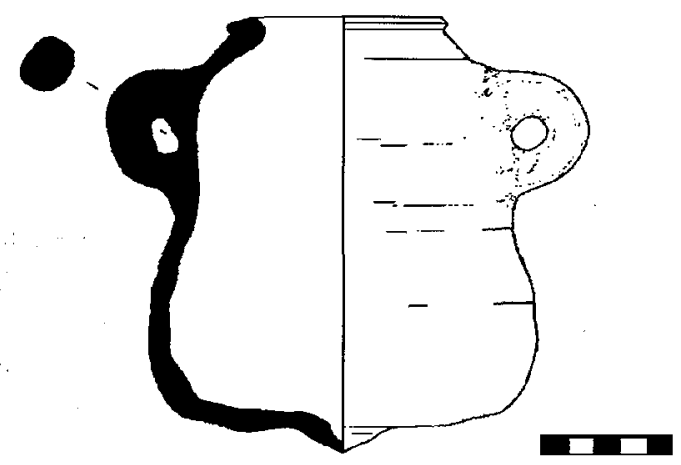

Figura 8: Ajuar cerámico del nivel G (Tendero Porras, e.p.).

mos Fernández, 1975), obviamente de muy difícil datación pero suficientes al menos para postular la existencia de una fase anterior, en principio, al periodo pleno.

En el cuadro $4 \mathrm{C}$ ya comentamos la proliferación de sondeos y la dificultad de interpretar alguno de ellos. En cualquier caso puede documentarse la presencia de esta fase antigua en la práctica totalidad de los mismos. En la campaña de 1964 se alcanza un nivel G que contiene cerámicas PT, CM, CC, ANF, GR y fragmentos realizados a mano (Ramos y Ramos, 1966); la llevada a cabo en 1969 (Ramos y Ramos, op. cit.) vuelve a repetir el hallazgo de cerámica PT y CC mientras que la de 1970 insiste en estos últimos tipos añadiendo la cerámica $\mathrm{GR}$.

Respecto al substrato donde descansaría este nivel $\mathrm{G}$, los datos son un tanto contradictorios pues mientras en ocasiones se afirma que por debajo de este horizonte aparece el "piso virgen" (Ramos Folqués, 1962b, 92), no es menos cierto que en la campaña de 1970 sí se habría alcanzado un nivel inferior, el $\mathrm{H}$ en este caso (Ramos y Ramos, 1976). La constatación de este último hecho nos lleva a considerar que, en efecto, en este sector parece existir hábitat por debajo de este asentamiento ibérico antiguo. Hemos de tener en cuenta además que para alcanzar estos niveles que relatamos debe rebajarse el terreno unos 4-5 $\mathrm{m}$ y ello conllevaría sin duda serios problemas de tipo logístico e incluso para la seguridad personal que aconsejaban la finalización del sondeo, de ahí que en ocasiones, tal vez, los sondeos no alcanzaran toda la profundidad posible.

Por lo que se refiere a los cortes más orientales -básicamente el 5F (Ramos Fernández, 1982 y 1983a)- se señala la presencia de un nivel $G$ con cerámicas importadas a torno -sin especificar tipos y formas-, ollas de orejetas (sic) y otras PT y CC con decoración incisa en el cuello.

Por desgracia, carecemos de un estudio pormenorizado de esos fragmentos a torno importados que se citan u otros de anteriores campañas, los cuales sin duda podrían ofrecer una cronología bastante concreta; nuestras pesquisas no han logrado identificarlos con claridad entre los fondos del Museo de La Alcudia.

La descripción más detallada de éstos la ofrece A. Ramos Folqués en su última obra sobre la cerámica de La Alcudia (Ramos Folqués, 1990) y es digno de resaltar el interés del autor por intentar clasificar los fragmentos según sus características de pastas y decoraciones. Así, señala la presencia de cerámicas que considera como "jónicas", otras de fabricación "ática antigua", un tercer grupo definido por su "engobe blanco", otro más caracterizado por la "pintura blanca" y finalmente las 
"bícromas" y las de "engobe rojo", éstas muy probablemente de origen semita. Las primeras incluirían un lote de cerámicas con pastas pardo-rojizas, granulosas y micáceas, con engobe blanco-amarillento y pintura roja o negra, mientras que las de origen ático las define a partir del engobe negro que las recubre. Ciertamente el trabajo es encomiable pero se echa en falta un análisis formal que pudiera conllevar la búsqueda de paralelos en los lugares de procedencia aducidos y, con ello, el establecimiento de cronologías más precisas. En esta línea se inscriben algunos trabajos como el de R. Olmos, que cita la existencia en el yacimiento de un pequeño kylix ático del tipo attic lip cup datable a mediados del s. VI aC (Olmos Romera, 1990), o el de P. Rouillard, que constata entre el repertorio de piezas griegas del yacimiento la existencia de un asa de un ANF de la Grecia del Este, del s. VI aC, o el borde de un ANF masaliota del tipo 2 de Py, de la primera mitad del s. V aC (Rouillard, 1991). En cualquier caso el hecho de que Ramos Folqués no mencione el contexto preciso sobre el hallazgo de tales piezas relativiza bastante el dato e incluso hay que valorar la posibilidad de que puedan corresponder a un horizonte anterior.

En cuanto al material local, en una visión de conjunto los contextos arqueológicos obtenidos muestran claras concomitancias entre las que merece la pena destacar la ausencia de cerámica a mano, o al menos su carácter residual -pues sólo se documenta en uno de los sondeos-, y la presencia simultánea de los tipos cerámicos habituales de época ibérica antigua, destacando la cerámica GR o el hallazgo de algunas formas características de este horizonte como son las urnas de orejetas o las ollas de cocina de labio exvasado y decoración incisa en el cuello (Fig. 8), esta última con claros paralelos en el repertorio vascular del cercano poblado de El Oral (Abad y Sala, 1993; Abad et alii, 2001). Estos últimos paralelos aducidos permitirían una aproximación cronológica para este nivel $\mathrm{G}$ grosso modo de los ss. VI-V $\mathrm{aC}$, a la espera, insistimos, de una deseable revisión de las piezas importadas citadas más arriba.

En lo que respecta a los sondeos más meridionales, fundamentalmente los localizados en los cuadros $10 \mathrm{~A}$ y $10 \mathrm{D}$, la información arqueológica es cualitativamente muy destacable pues, según los datos publicados, por debajo del estrato $F$ no aparecerían otros sedimentos con evidencias materiales, lo que abre la puerta a la hipótesis de que el oppidum de la fase antigua fuera sensiblemente inferior a los establecimientos que le suceden. Es preciso recordar en este punto a E. Albertini (Albertini, 1906 y 1907) que, como ya dijimos, definió con precisión el estrato natural compuesto de arenas y arcillas estériles que aparecía en la base de sus trincheras. Después sería A. Ramos Folqués quien alcanzaría el nivel más bajo ( $R a-$ mos Folqués, 1962b), que define como "tierra o piso virgen" (Ramos Folqués, 1966, 74). Esta misma expresión la repite al tratar los sondeos más orientales -6F y 7F- (Ramos Folqués, op. cit.).

En lo referente a la excavación del "templo", ya hemos comentado que no encontramos evidencias materiales que permitan llevar su datación inicial hasta el s. VI aC, por lo que si, como parece, los estratos correspondientes al nivel fundacional del edificio son los más profundos del sector, habrá que convenir que la base de la estratigrafía se inicia a partir de la fase plena, en un momento indeterminado del último tercio del $\mathrm{s} . \mathrm{V}$ aC.

En consecuencia, da la sensación que la mitad meridional de la superficie del yacimiento no parece estar ocupado antes de mediados-último tercio del s. $\mathrm{V}$ aC, de lo que obviamente se infiere una menor extensión para el núcleo de época ibérica antigua. Nosotros hemos propuesto recientemente (Moratalla Jávega, 2003) una extensión para este núcleo antiguo en torno a las $3 \mathrm{Ha}$, si bien esta cifra hemos de considerarla como meramente orientativa pues desconocemos el punto exacto en el que la estratigrafía comienza a documentar este nivel G. Dando por hecho su constatación en los sectores $3 F, 4 C$ y $5 F$-aquí se llega a decir literalmente a propósito de este estrato que ha sido "plenamente identificado por vez primera en este yacimiento" (Ramos Fernández, 1982, 119)-, nos faltan jalones que permitan localizar con precisión el área ocupada por este oppidum antiguo si bien la tendencia muestra que sería hacia la mitad septentrional donde se localizan los niveles más antiguos, de ahí la cifra ofrecida que, insistimos, tiene ese carácter provisional que señalamos. Si la hipótesis fuera correcta, resulta obvio que la ciudad de la fase plena habría duplicado el asentamiento antiguo, fenómeno demográfico que habria que relacionar con algún tipo de sinecismo desplegado por el oppidum en su entorno y que, no por casualidad, coincidiría con el periodo de mayor esplendor de la ciudad ibérica, aquélla que conoció la más rica y variada producción escultórica. 


\section{4. La "ciudad" protohistórica}

Los mismos sectores donde se documenta el nivel $G-3 F, 4 C$ y $5 F$-prolongan su secuencia estratigráfica en profundidad hasta contextos materiales propios de época pre $y / 0$ protohistórica, si bien resulta extraordinariamente complicado atribuir una datación, ni cronológica ni cultural, a los mismos. Ello es así en gran medida porque este estrato $\mathrm{H}$ ha funcionado durante largo tiempo como auténtico cajón de sastre donde situar los materiales prehistóricos del yacimiento, tanto líticos como cerámicos o metálicos, desde los considerados eneolíticos hasta los propiamente de la edad del Bronce (p.ej. Ramos Fernández, 1975). Esta interpretación, excesivamente genérica, se torna más confusa todavía cuando se pretende incluir en el mismo las relevantes piezas del bronce final u orientalizantes halladas en el yacimiento -recordemos las "hachas" de apéndices laterales (Monteagudo, 1977) o la identificación de ánforas fenicias (GilMascarell y Aranegui, 1981, 54)-. Parece muy poco probable que todo ello apareciera en un único nivel y más bien habria que pensar en la existencia de varios. Este hecho viene a demostrar los efectos perniciosos que puede tener el mantenimiento a rajatabla de una determinada secuencia estratigráfica pues, andando el tiempo, se hace necesaria "entibarla" mediante determinadas proposiciones ad hoc que no hacen más que poner en tela de juicio la hipótesis inicial, e inamovible, al tratar de adecuarla al ritmo de las investigaciones, justificación que es síntoma ineludible de que, permítasenos la expresión, el edificio hace aguas.

Hasta la década de los 70 del siglo pasado la investigación arqueológica podía dar por buena la columna presentada, pero desde el momento en que son identificados, y datados, determinados elementos arqueológicos, se requiere un reajuste de la secuencia, que no en pocas ocasiones provoca un cierto "baile" de determinadas piezas. Sirva como ejemplo el caso de las "hachas" de apéndices laterales, piezas que hoy sabemos son propias de contextos de los ss. VIII-VII aC (González Prats, 1990): en sucesivas publicaciones pasan ${ }^{13} \mathrm{del}$ estrato G (Ramos Fernández, 1982) al H (Ramos Fernández, 1983b, 32) y, nuevamente, al $G$ (Ramos Folqués, 1990). O como cuando se pretende solucionar los desajustes aparecidos a costa de "hacer desaparecer" el componente ibérico antiguo del estrato $\mathrm{G}$, que pasa así a ser considerado un estrato datado entre mediados del s. VII y finales del VI aC (Ramos Fernández, 1983b), al tiempo que se adelanta la cronología inicial del nivel $F$ hasta ese s. VI aC, con lo que este último estrato pasa nada menos que a durar desde fines de esa centuria hasta el $228 \mathrm{aC}$, circunstancia que no habla precisamente en pro del dinamismo de una ciudad de la categoría que debió tener La Alcudia ibérica. Resulta obvio que estas vacilaciones vienen determinadas por el empeño en mantener la secuencia tradicional, cuando hubiera resultado bastante más sencillo abrir la serie a otros niveles que reflejaran con más exactitud le evolución estratigráficocronológica. Como ya hemos defendido, el ajuar cerámico del estrato $G$ muestra indicios más que suficientes para proponer su adscripción cultural al horizonte ibérico antiguo como en el fondo se reconoce en una de las últimas publicaciones de $\mathrm{R}$. Ramos sobre la secuencia estratigráfica en el yacimiento (Ramos Fernández, 1996)-, de modo que habrá que concluir que bajo este nivel $G$ deben desarrollarse más fases de habitación que la que tradicionalmente recoge el estrato $\mathrm{H}$, de ahí, por ejemplo, que nosotros hayamos optado por señalar la existencia de un nivel "Pre-H" en alguno de los sondeos que se muestran en la figura 3.

Volviendo a nuestro análisis de la estratigrafía, el estrato $\mathrm{H}$ se menciona en el sondeo $3 \mathrm{~F}$ conteniendo cerámica PT y a mano (Ramos Fernández, 1975). En 4C se documenta en la campaña de 1970 refiriendo el mismo material, aunque se añade respecto a algún fragmento PT a torno que es de "barro rojo con engobe blanco al exterior" (Ramos y Ramos, $1976,29)$. En cuanto al cuadro $5 F$, ya hemos comentado la alteración de la secuencia tradicional al adscribir a un horizonte de los ss. VII-VI aC los materiales del estrato G (Ramos Fernández, 1983a, 172); si nuestra hipótesis es correcta, dicho contexto efectivamente debe datarse dentro de esa horquilla pero ello no debe implicar la desaparición del horizonte ibérico antiguo, aquí "devorado" por el potente estrato F. En consecuencia, el nivel G debería adjudicarse a ese horizonte perdido, mientras que las piezas orientalizantes se corresponderían con el estrato $\mathrm{H}$, tal y como se

\footnotetext{
13 Recuérdese que este conjunto de alrededor de medio centenar de "hachas" fue descubierto en el s. XIX por A. Ibarra (Ibarra y Manzoni, 1981), sin que se sepa en qué condiciones se produjo este sobresaliente hallazgo.
} 
documenta en los sectores $3 \mathrm{~F}$ y $4 \mathrm{C}$, donde conviven piezas a torno y otras realizadas a mano. La conclusión última sería que, en el caso del cuadro 5F, debe existir una fase de ocupación anterior -que nosotros hemos denominado "Pre-H"- bien identificada por un ajuar compuesto por "molinos de mano barquiformes, cuencos y escudillas de pasta gris con desengrasantes micáceos y modeladas a mano, hachas de piedra pulida y útiles de sílex" (Ramos Fernández, op. cit.). No está de más traer a colación un nuevo argumento que apoyaría esta división en dos, como poco, del registro material que venimos estudiando y es el relativo a la presencia de piezas de sílex. Estos elementos arqueológicos son un auténtico indicador de los horizontes prehistóricos, desapareciendo por completo de los ajuares cotidianos en poblados muy cercanos a La Alcudia -Peña Negra o Saladares- al menos desde el s. VIII aC (González Prats, 1990, 86), por lo que parece plausible postular en el caso de La Alcudia un horizonte prehistórico culturalmente poco definido en las referencias consultadas- por debajo de un nivel propio de los ss. VII-VI aC. Todo ello viene a coincidir en este sector $5 \mathrm{~F}$, que se definiría así como el punto de habitación original en todo el altozano, carácter que, en cierto modo, pervive por ser ésta la zona donde se levanta el caserón de la familia Ramos.

En suma, podemos encontrarnos ante un fenómeno similar al documentado en el tránsito de la fase ibérica antigua a la plena, esto es, desde un hábitat prehistórico primigenio que posiblemente no superaría $1 \mathrm{Ha}$, el poblado crecería a partir del horizonte bronce finalorientalizante hasta alcanzar unas cifras que en principio se mantendrían durante la fase ibérica antigua, lo que obviamente habla a favor de una consolidación del hábitat, que llega a ser ciertamente atractiva para su entorno inmediato, probablemente en función de los excelentes recursos que ofrece el ecosistema donde se asienta el núcleo (Grau y Moratalla, 2004): cerca de buenas tierras y de zonas marismeñas, en posición centrada en la comarca y bien comunicado en todas direcciones.

\section{ALGUNAS CONCLUSIONES ESTRA- TIGRÁFICAS}

Desde el punto de vista del análisis estratigráfico que permiten los datos publicados sobre La Alcudia ibérica, lo primero que creemos necesario reseñar es que no parece que exista una secuencia-tipo inamovible para todo el yacimiento: existen estratos intermedios en sectores puntuales del mismo -como pocoy tampoco se repite en toda la loma la misma secuencia, especialmente larga según parece en el sector $5 \mathrm{~F}$.

El hecho no debe resultar sorprendente. La ciudad debió crecer como un ser orgánico que es, con sus inicios, su consolidación, sus fases de apogeo -sin duda una de ellas durante la cultura ibérica- y su decadencia física, tradicionalmente relacionada con el periodo tardo-romano y visigodo. Esta evolución se debe tener como razonable y lógica, lo contrario sería lo inusual, y ello obviamente trasciende a su papel gestor sobre el territorio circundante, que sin duda lo tuvo, incluso en sus fases menos esplendorosas, con una serie de picos y valles a lo largo de su dilatada vida que ofrecerian un mayor o menor magnetismo de alcance espacial variable sobre las tierras que la rodean. No es posible colocar equilibradas en la balanza fases tan dispares como podían ser el horizonte orientalizante, la cultura ibérica - la colonia romana, esta última sin duda con un estatuto jurídico-político superior al que pudo llegar a alcanzar en su periodo ibérico de mayor expansión, muy probablemente el horizonte de época plena. Los condicionantes históricos son otros y también diferente debió ser, cualitativa y cuantitativamente, el papel rector que desempeñó la ciudad.

Por otro lado, la cronología de las fases ibéricas, y a excepción de esos estratos intermedios citados, parece esencialmente correcta como se presenta tradicionalmente. Las piezas más modernas del nivel $F$ apuntan al tránsito del s. III al II para fijar, sin ruptura estratigráfica aparente, el arranque del nivel $E$, que por otro lado acabaría en un momento arqueológicamente poco determinado del s. I aC. El nivel $G$, que por contexto material representa con bastante nitidez un horizonte ibérico antiguo, no ofrece por el momento una datación clara para establecer el inicio de la fase plena; sólo algunas piezas importadas, pendientes de un pormenorizado estudio, podrían arrojar algo de luz sobre este particular. Lo mismo cabe decir de los horizontes anteriores, y hablamos en plural porque estamos convencidos de la necesidad de establecer al menos una frontera entre el material del horizonte bronce final-orientalizante y el propio de la edad del Bronce. 
Todo ello no refleja sino la necesidad de seguir investigando los riquísimos fondos materiales que se encierran en el Museo de La Alcudia, de los que este artículo no es sino una breve reflexión fundamentalmente bibliográfica de lo que, sin duda, está por venir. La segunda parte de esta nueva época debe venir estructurada a partir del reinicio de las excavaciones, no sólo de los niveles ibéricos obviamente, llevadas a cabo con todas las exigencias metodológicas que hoy en día exige la disciplina. Alguna intervención se ha realizado ya que muestra bien a las claras la complejidad estratigráfica del asentamiento (Abad et alii, 2000). Tiempo habrá para corroborar o refutar las ideas que este artículo plantea, pero en cualquier caso considerábamos necesario comenzar por una previa reflexión sobre lo realizado, que en lo tocante al mundo ibérico es bastante menos de lo que se acostumbra a creer, para ubicar en unas coordenadas espacio-temporales más ajustadas el papel que desempeñó el yacimiento.

Efectivamente, todo ello no es óbice para seguir considerando a La Alcudia como el principal y más trascendente oppidum ibérico de las comarcas meridionales del País Valenciano, incomparable en multitud de variables arqueológicas -perduración de la secuencia, tamaño, cultura material, conversión en colonia romana, etc- respecto al resto de núcleos ibéricos; sin duda -y sirva esta paráfrasis como emocionado recuerdo a la figura de don Enrique Llobregat- nos encontramos ante la única gran ciudad de toda la Contestania.

Prof.Jesús Moratalla Jávega
Area de Arqueología
Dpto. de Prehistoria, Arqueología,
Ha Antigua, Filología Griega y $_{\text {Filología Latina }}$
Facultad de Filosofia y Letras
Universidad de Alicante
Apdo. 99
03080 Alicante
jesus.moratalla@ua.es

\section{BIBLIOGRAFÍA}

ABAD CASAL, L. y F. SALA SELLÉS, 1993: EI poblado ibérico de El Oral (San Fulgencio, Alicante), Trabajos Varios del S.I.P., 90, Valencia.

ABAD CASAL, L., MORATALLA JÁVEGA, J. y TENDERO PORRAS, M., 2000: "Contextos de Antigüedad Tardía en las termas occidentales de La Alcudia (Elche, Alicante)", Anales de Prehistoria y Arqueología, 16, 133-147.

ABAD CASAL, L., SALA SELLÉS, F. (eds.), GRAU MIRA, I., MORATALLA JÁVEGA, J., PASTOR MIRA, A. y
TENDERO PORRAS, M., 2001: Poblamiento ibérico en el Bajo Segura. El Oral (II) y La Escuera, Bibliotheca Archaeologica Hispana, 12, Alicante-Madrid.

ALBERTINI, E., 1906: "Fouilles d'Elche", Bulletin Hispanique, VIII, 333-362.

ALBERTINI, E., 1907: "Fouilles d'Elche", Bulletin Hispanique, IX, 1-17 y 109-130.

ALFÖLDY, G., 2003: "Administración, urbanización, instituciones, vida pública y orden social", Canelobre ("Las ciudades y los campos de Alicante en época romana), 48, 35-57, Alicante.

ÁLVAREZ GARCÍA, N., 1997: "El almacén del templo A: aproximación a espacios constructivos especializados y su significación socio-económicas", en M. OLCINA DOMĖNECH (ed.): La Illeta dels Banyets (El Campello, Alicante). Estudios de la Edad del Bronce y Época lbérica, 133-174, Alicante.

ARRIBAS, A., TRİAS, M. G., CERDÀ, D. y DE HOZ, J., 1987: El barco de El Sec (Calvià, Mallorca). Estudio de los materiales, Palma de Mallorca.

GIL-MASCARELL, M. y ARANEGUI GASCÓ, C. 1981: El Bronce Final y el comienzo de la Edad del Hierro en el País Valenciano, Monografías del Laboratorio de Arqueología de Valencia, $n^{\circ} 1$, Valencia.

GONZÁlEZ PRATS, A., 1990: Nueva luz sobre la Protohistoria del Sudeste, Alicante.

GRAU MIRA, I. y MORATALLA JÁVEGA, J., 2004: "EI paisaje antiguo", Catálogo de la Exposición "Iberia, Hispania, Spania. Una mirada desde llici (Alicante, 2004)", Alicante.

IBARRA $Y$ MANZONI, A., 1981: Illici, su situación y antigüedades, Alicante, Reproducción facsímil de la edición de Establecimiento Tipográfico de Antonio Reus, Alicante, 1879.

LLOBREGAT CONESA, E. A., 1972: Contestania Ibérica, Alicante.

LLOBREGAT CONESA, E. A:, 1994: "Tradición religiosa fenicio-púnica en Contestania", Coloquio "El Mundo Púnico. Historia, Sociedad y Cultura" (Cartagena, 1990), 169-175, Murcia.

MOLINA VIDAL, J., 1997: La dinámica comercial romana entre Italia e Hispania Citerior, Alicante.

MONTEAGUDO, L., 1977: Die Beile auf der Iberischen Halbinsel, Prähistorische Bronzefunde, IX, 6, München.

MORATALLA JÁVEGA, J., 2003: Organización del territorio y modelos de poblamiento en la Contestania ibérica, Tesis Doctoral, inédita, Universidad de Alicante.

MORATALLA JÁVEGA, J., e.p.: "El territorio meridional de la Contestania", en Jornadas de Arqueología "La Contestania Ibérica, treinta años después" (Alicante, 2002), Alicante.

OLCINA DOMÉNECH, M. H., y SALA SELLÉS, F., 2000: "Las cerámicas de barniz negro en el área sur alicantina", Taula Redona "La ceràmica de vernis negre dels segles II I aC: centres productors mediterranis i comercialització a la Peninsula lbérica (Empúries, 1998), 107-127, Mataró.

OLMOS ROMERA, R., 1990: "Original elements and Mediterranean stimuli in iberian pottery: part $2^{\prime \prime}$, Mediterranean Archaeology, 3, 101-109.

PRINCIPAL-PONCE, J., 1998: Las importaciones de vajilla fina de barniz negro en la Cataluña sur y occidental durante el siglo III aC., B.A.R. International Series 729, Oxford.

RAMÓN, J., 1990-91: "Barrio industrial de la ciudad púnica de Ibiza: el taller AE-20", Cuadernos de Prehistoria y Arqueología de Castellón, 15, 247-285.

RAMOS FERNÁNDEZ, R., 1975: La ciudad romana de llici, Alicante. 
RAMOS FERNÁNDEZ, R., 1982: "Precisiones para la clasificación de la cerámica ibérica”, Lucentum, I, 117133.

RAMOS FERNÁNDEZ, R., 1983a: "Estratigrafia del sector 5-F de La Alcudia de Elche", Lucentum, II, 147-172.

RAMOS FERNÁNDEZ, R., 1983b: La Alcudia de Elche, Publicaciones de la Caja de Ahorros de Alicante y Murcia, 172, Alicante.

RAMOS FERNÁNDEZ, R., 1995: El templo ibérico de La Alcudia. La Dama de Elche, Elx.

RAMOS FERNÁNDEZ, R., 1996: "La Alcudia y la Dama de Elche", Archivo de Arte Valenciano, año LXXVII, 19-23.

RAMOS FERNÁNDEZ, $R$ y LLOBREGAT CONESA, E.A., 1995: "Un templo ibérico en La Alcudia de Elche", $X X \mid$ C.N.A. (Teruel, 1991), vol. 3, 949-959.

RAMOS FOLQUÉS, A., 1933: "Nuevos descubrimientos en Illici”, Archivo Español de Arte y Arqueología, 26, 103111.

RAMOS FOLQUÉS, A., 1941: "Nuevas excavaciones en La Alcudia de Elche", Corona de Estudios que la sociedad española de antropología, etnografia y prehistoria dedica a sus mártires, 287-299, Madrid.

RAMOS FOLQUÉS, A., 1943: "Hallazgos cerámicos de Elche $y$ algunas consideraciones sobre el origen de ciertos temas", AEspA, XVI, n 52, 328-335.

RAMOS FOLQUÉS, A., 1950: "Hallazgos escultóricos en La Alcudia de Elche", AEspA., XXIII, n 81, 353-359.

RAMOS FOLQUÉS, A., 1956: "Memoria de las excavaciones practicadas en La Alcudia. Elche (Alicante)", N.A.H., IIIIV, 1-3, 102-113.

RAMOS FOLQUÉS, A., 1962a: Memoria de las excavaciones efectuadas en La Alcudia (Elche) en 1961, E.A.E., 8, Madrid.
RAMOS FOLQUÉS, A., 1962b: "Excavaciones en La Alcudia", N.A.H., V, 91-97.

RAMOS FOLQUÉS, A., 1966: "Estratigrafía de La Alcudia de Elche", Saitabi, XVI, 71-76.

RAMOS FOLQUÉS, A., 1990: Cerámica ibérica de La Alcudia (Elche-Alicante), Alicante.

RAMOS FOLQUÉS, A. y RAMOS FERNÁNDEZ, R., 1966: "Memoria de las excavaciones practicadas en La Alcudia de Elche, en el año 1964", N.A.H., VIII-IX, 1-3, 214-219.

RAMOS FOLQUÉS, A. y RAMOS FERNÁNDEZ, R., 1976: Excavaciones en La Alcudia de Elche durante los años 1968 al 1973, E. A. E., 91, Madrid.

RAMOS MOLINA, A., 1997: La planimetria del yacimiento de La Alcudia de Elche, Alicante.

ROUILLARD, P., 1991: Les grecs et la Péninsule lbèrique du VIII au IV siècle avant Jésus-Christ, Publications du Centre Pierre Paris, 21, París.

SALA SELLÉS, F., 1992: La «tienda del alfarero» del yacimiento ibérico de La Alcudia, Alicante.

SANMARTI-GREGO, E., 1978: "L'Atelier des patères á trois palmettes radiales et quelques productions connexes", Archéologie en Languedoc, 1, 21-36.

TENDERO PORRAS, M., e. p.: "La cerámica del periodo ibérico antiguo en La Alcudia (Elche, Alicante)", Jornadas de Arqueología "La Contestania Ibérica, treinta años después" (Alicante, 2002), Alicante.

TORTOSA ROCAMORA, T., 1998: "Los grupos pictóricos en la cerámica del sureste y su vinculación al denominado estilo Elche-Archena", Actas del Congreso Internacional "Los Iberos. Príncipes de Occidente" (Barcelona, 1998), 207-216, Barcelona.

VANDERMERSCH, C., 1994: Vins et amphores de Grande Grèce et de Sicilie $I V^{\mathrm{e}}-\| I^{\mathrm{e}}$ s. avant J.-C., Naples. 